\title{
CAN HUGE MARKET PROFITS OF THE BEST INVESTORS BE EXPLAINED BY A LOTTERY WINNER'S LUCK?
}

\author{
Tommi P. Laiho ${ }^{1}$ \\ ${ }^{1}$ Rymättylänkatu 19 B 6, 20740, TURKU, FINLAND, tommi.p.laiho@protonmail.com, \\ $+358-400-593477$
}

\begin{abstract}
In the years 1994-1996, I started to think about how much meaning luck has when trading stocks, FOREX, and corresponding derivatives. Therefore, I developed a simple formula, which describes how much your capital can grow if you have a rare lottery winner's luck when investing in volatile markets. In the end I found that indeed, you need the luck of a Finnish lottery winner to expand your little capital to extreme heights, especially when trading with highly volatile stock index derivatives. If we assume that markets are fully competitive, extremely volatile, and even inside information is useless when trying to trade in a profitable way, by using this simple formula, we can see that even a relatively small amount of capital can grow to an extremely large sum of money.
\end{abstract}

\section{Keywords}

Random walk theory, stock index derivatives, luck, lottery

\section{JEL Classification}

\section{G17}

DOI: https://doi.org/10.14311/bit.2019.02.04

Editorial information: journal Business \& IT, ISSN 2570-7434, CreativeCommons license (c) (i) published by CTU in Prague, 2019, http://bit.fsv.cvut.cz/ 


\section{Introduction}

Even though an individual realizes that it is a very rare phenomenon that he might win in a Finnish lottery game, we can still witness that almost every weekend somebody does win in this very difficult to win, luck-based money game. The odds of winning are $1 / 18,643,560$. The Finnish population is about 5,6 million people. So, there is a small group of Finnish citizens every year that has this enormous luck. Furthermore, it must be said that this kind of money game is very popular among Finns, so it is not that surprising that somebody wins in this game, which is based on luck only. There are also people who avoid this kind of lottery gamer's risk and invest in stocks or stock index derivatives instead which are of course a much more volatile investment. This sounds at first a much more rational and less luckbased way but soon investments on stock index derivatives show that money is often lost by making wrong decisions. Wrong decisions happen most likely on the markets which are effective and random walk theory starts to play a significant role in making investment decisions. It is good to bear in mind that based on random walk theory, there is no chance to really predict the movements of the stock index. That is because all relevant data that truly effects stocks and stock derivatives already exists in the price; therefore, the latest unpredictable news and its effect on the stock index price is always a surprise. In the end, within the time period that is long enough, it is nearly impossible to predict the movements of the stock market index. On the other hand, if you have a lottery winner's luck it is indeed possible without any understanding of the fundamental laws of investing.

\section{Theoretical basis}

In the following model there are the following assumptions:

1. Markets are very volatile, and it is easy to multiply your capital if you know where the markets are heading.

2. Markets are so competitive that even inside information is useless.

3. The volume of trade is very high.

4. Therefore random walk theory works in these markets with full effort and there are no anomalies.

The model shows that even a very small amount of capital, let's say $\$ 1,000$, can be expanded to tredecillions on this kind of market. However, a lottery winner's luck is needed - but we know that even a country with such a small population, like Finland produces tens of millionaires every year.

So how to conclude my simple mathematical model based on these assumptions?

It happens like this:

1. $\$ 1,000$ is the capital.

2. 2 is the multiplier of the capital on every investment decision. It is relatively easy to achieve a multiplier 2 on a volatile stock index derivatives market if you know where the market is heading.

3. The luck of the investor is as good as the odds of a lottery winner in Finland, which currently is $1 / 18,643,560$.

4. The possibilities for success are roughly $1 / 2$. In other words, the stock index is going up or down on a volatile market.

Therefore:

$\left(\frac{1}{2}\right)^{X}=\frac{1}{18,643,560}$ 
Now we will find out the $X$ from the formula:

$X \cdot \ln \left(\frac{1}{2}\right)=\ln \left(\frac{1}{18,643,560}\right)$

$X=\frac{\ln \left(\frac{1}{18,643,560}\right)}{\ln \left(\frac{1}{2}\right)}$

$X \approx 24,152$

Now we know that we can double the $\$ 1,000$ capital approximately 24,152 times.

$X=\$ 1,000 \cdot 2^{\left(\frac{\ln \left(\frac{1}{18,643,560}\right)}{\ln \left(\frac{1}{2}\right)}\right)}$

$X=\$ 1,000 \cdot 2^{\left(\frac{\ln (18,643,560)}{\ln (2)}\right)}$

$X=\$ 1,000 \cdot 18,643,560$

$X=\$ 18,643,560,000$

You certainly have enough money then $-\$ 18,643,560,000$. In general, the formula looks like this:

Expansion of the capital $=$ capital $\cdot$ multiplier of the capital $\left(\frac{\ln (\text { Probability based on the population size })}{\ln (\text { Probability of success })}\right)$

$E=c m^{\left(\frac{\ln (P 1)}{\ln (P 2)}\right)}$

\section{Conclusion and discussion}

My point is that the investor believes that he can predict the future, but this cannot be the case in effective markets. This investor may think that he has superior intellectual skills, is able to perform some witchcraft or may have similar kind of irrational beliefs. There are lots of people on Wall Street who do plenty of research on existing companies and try to predict their performance. Many of these people may be smart, but still, all these attempts are truly pointless without significant luck in the competitive markets if somebody wants to become truly rich.

\section{References}

[1] VEIKKAUS Oy. Todennäköisyys. www.veikkaus.fi. Available online at: https://www.veikkaus.fi/fi/lotto\#!/ohjeet/peliohjeet/todennakoisyys (accessed 16 Sep 2019)

[2] Statistics Finland. Population. www.tilastokeskus.fi. Available online at: https://www.tilastokeskus.fi/tup/suoluk/suoluk_vaesto_en.html (accessed 16 Sep 2019)

[3] Aldous, David; Fill, James Allen. Reversible Markov Chains and Random Walks on Graphs, 2002. Archived from the original on 27 February 2019.

[4] EUGENE F. Fama. The Behavior of Stock-Market Prices, 1965. Journal of Business, XXXVIII (1), January pp. 34-105. ISSN: 00219398.

[5] Andrew W. Lo. Market Efficiency: Stock Market Behavior in Theory and Practice. VOLUME 1 Market Efficiency, 1997. pp. 31. ISBN-13:978-1858981611. 